\title{
The Evolution of Neuroendocrine Tumor Treatment Reflected by ENETS Guidelines
}

\author{
Wouter T.Zandee Wouter W. de Herder \\ Endocrinology Sector, Department of Internal Medicine, ENETS Centre of Excellence, Erasmus MC and Erasmus MC \\ Cancer Institute, Rotterdam, The Netherlands
}

\section{Keywords}

Neuroendocrine tumor · First-/second-line treatment .

ENETS Guidelines

\begin{abstract}
In 2016, the third version of guidelines for the diagnosis and treatment of neuroendocrine tumors (NETs) has been published by the European Neuroendocrine Tumor Society (ENETS). These guidelines reflect the progress in treatment of NETs, and by comparing the newest guidelines with the first guidelines of 2001, this progress can be clearly recognized. Diagnostic accuracy has been increased by the introduction of PET-CT with Ga-labelled somatostatin analogs, and multiple new treatments and treatment schedules have been developed, like peptide receptor radiotherapy with radiolabeled somatostatin analogs, or targeted therapies. Evidence and indications for these therapies are discussed in the ENETS guidelines. In this review, we aim to show the progress in NET diagnosis and treatment on the basis of the advances in the guidelines, but also to discuss the unsolved questions and unmet needs which still remain.
\end{abstract}

(C) 2018 The Author(s)

Published by S. Karger AG, Basel

\begin{tabular}{ll}
\hline KARGER & ( 2018 The Author(s) \\
& Published by S. Karger AG, Basel Openger \\
E-Mail karger@karger.com & This article is licensed under the Creative Commons Attribution- \\
www.karger.com/nen & NonCommercial-NoDerivatives 4.0 International License (CC BY- \\
NC-ND) (http://www.karger.com/Services/OpenAccessLicense). \\
Usage and distribution for commercial purposes as well as any dis- \\
tribution of modified material requires written permission.
\end{tabular}

\section{Introduction}

In 2004, the European Neuroendocrine Tumor Society (ENETS) was founded by a group of European medical specialists in the field of neuroendocrine tumors (NETs). The main goal of the society since then has been "to integrate basic and clinical research with teaching and to establish guidelines for the diagnosis and therapy for gastroenteropancreatic neuroendocrine tumors" [1]. The first guideline of this European consortium was a consensus paper in 2001 on the imaging of NETs associated with the Multiple Endocrine Neoplasia type 1 (MEN-1) syndrome [2]. This paper was the result of a Delphi process initiated in 1998 by the European Network for Neuroendocrine Tumors, ENET. ENET was the basis on which ENETS was founded. The first set of guidelines by ENETS was published in 2004, and in 2016 the third version of these guidelines was published. In 2017, the second version of the ENETS Standards of Care was published, thereby pursuing one of the main goals of the society. In this review, we will discuss the impact of these guidelines and standards on the clinical practice for patients with a NET over the recent years. 


\section{Radiological and Nuclear Imaging}

If a NET is suspected, the first guidelines of 2001 by ENET advocated a chest X-ray and abdominal ultrasonography as the imaging procedures of first choice [2]. In both functional and nonfunctional NET syndromes, somatostatin receptor-scintigraphy (SRS) was advised with a reported sensitivity and specificity at that time of 90 and $80 \%$, respectively. At this stage, only ${ }^{111}$ In-pentetreotide planar and SPECT images were available. Thereafter, CT and MRI were additionally performed for staging and for follow-up to document progression. SRS was already discussed to have limited use in localized insulinomas. If this was due to the small size of insulinomas or the expression profile of the somatostatin receptor subtypes was still unclear [3]. In case of a negative SRS, an enteroclysis was advised in patients with metastatic NETs from an unknown primary source. At that time, ${ }^{18} \mathrm{FDG}-\mathrm{PET} / \mathrm{CT}$ was considered not to be useful in the diagnostic workup. The guidelines written by ENET(S) in 2001 and 2004 advised to perform CT, or MRI in combination with SRS, without reporting on the limitations and evidence for these strategies $[2,4]$. For conventional imaging, the biggest improvement of the guidelines is that we can now substantiate the diagnostic strategies based on evidence and that this has helped us also to identify the limitations and pitfalls of the radiological and nuclear medicine modalities [5]. The sensitivity of CT is limited to $61-93 \%$ for detection of NETs, but its specificity is fairly high: reported to be between 71 and $100 \%$. However, it seems that many small lesions can still be missed with the use of 3-phase CT. Compared to thin slice histopathology, CT only detects $37.6 \%$ of liver metastases in patients undergoing a hemihepatectomy [6]. In these cases, superior imaging techniques could be used to exclude or identify patients for potential curative surgery. With the use of MRI, the detection rate of liver metastases already increased to $48.8 \%$ in the same study.

SRS was already fully in corporated in the first ENET(S) Standards and Guidelines. SRS has two specific advantages: it often detects more metastases - at more sites than conventional imaging, and it assesses the expression of somatostatin receptor subtypes on the tumor. The latter is required for peptide receptor radionuclide therapy (PRRT) using beta emitting somatostatin receptor radioligands and for the selection of somatostatin analogs (SSAs) as first-line treatment. SRS detects tumors that express the somatostatin receptor subtypes 2 , 3 , and 5 . These are mainly NETs, including pheochromocytomas and other paragangliomas, but also menin- giomas, medulloblastomas, and granulomatous diseases can display high expression of these somatostatin receptor subtypes. The first SRS used $\left[{ }^{123}{ }^{1-}-\mathrm{Tyr}^{3}\right]$ octreotide, but a large number of drawbacks (short half-life, hepatic clearance resulting in high liver uptake and costs) made the development of alternative radiolabeled analogs necessary [7]. SRS using ${ }^{111}$ In-pentetreotide (OctreoScan ${ }^{\circledR}$ ) was the most widely used SRS until very recently [8-11]. Currently, SRS with ${ }^{111}$ In-pentetreotide is rapidly losing ground to PET/CT with gallium-labeled SSAs, because there are distinct advantages to this technique. Patients can be injected with the gallium-labeled SSA $\left({ }^{68} \mathrm{Ga}-\mathrm{DO}-\right.$ TA-TOC/TATE/NOC) only $1 \mathrm{~h}$ in advance of the scanning procedure, whereas SRS can only be performed $24 \mathrm{~h}$ after injection of ${ }^{111} \mathrm{In}$-pentetreotide. But the main advantage of ${ }^{68} \mathrm{Ga}$-SSA PET/CT is its higher detection rate as compared to SRS. Sensitivity and specificity of ${ }^{68} \mathrm{Ga}$-SSA PET/CT for NET detection varies between 88 and $95 \%$ in several studies and outperforms SRS in head-to-head comparisons [12-16]. For detection of bone metastases, ${ }^{68} \mathrm{Ga}$-SSA PET/CT even outperforms the current gold standard: the ${ }^{99 \mathrm{~m}} \mathrm{Tc}$-bisphosphonates scintigraphy $[17,18]$. This makes ${ }^{68} \mathrm{Ga}-\mathrm{SSA}$ PET/CT the modality of choice for nuclear imaging in the current standards of care. The performance of the different gallium-labeled SSAs (either DOTA-TOC, DOTA-TATE or DOTA-NOC) shows only small variations thus no specific preference exists $[19,20]$. The most recent ENETS guidelines already anticipate this change in diagnostic approach [5].

Also, several studies have now shown the usefulness of ${ }^{18} \mathrm{~F}$-FDG-PET/CT in the diagnostic workup of NETs. The sensitivity for detecting NETs is generally relatively low, ranging from $37-72 \%$. Its usefulness, however, seems to be the better detection and prognostic stratification of higher grade NETs and neuroendocrine carcinomas (NECs). In tumors with high proliferation rates and subsequent dedifferentiation, there can be loss of somatostatin receptor expression with concomitant increase in glucose metabolism and thus FDG avidity [21]. Furthermore, FDG avidity is a negative prognostic sign and might even be superior to the MIB-staining of the Ki67 protein for predicting prognosis [22]. With the upcoming WHO 2017 guidelines for diagnosis and grading of NETs, the role of FDG-PET will be of most relevance for the diagnosis and therapeutic approach of patients with grade 3 NETs and NECs. Also, the combination of ${ }^{18}$ F-FDG$\mathrm{PET} / \mathrm{CT}$ and SRS imaging can be used to select patients for PRRT. Mainly high grade NETs, positive for FDG and SRS imaging, could benefit from PRRT [23]. 
Thus, combining FDG and ${ }^{68} \mathrm{Ga}-\mathrm{SSA}$ PET/CT will give the most complete picture of NETs. It is superior in detecting NETs, but the combination also gives a more complete picture of the biological behavior of the NET by knowing the SRS and FDG avidity.

\section{Pathology Diagnosis}

Selecting the optimal treatments and diagnostics for NET patients starts with making a correct diagnosis. This makes the Standards of Care on pathology reports of great value [24]. Uniform diagnosis is also required to be able to interpret results of trials and cohort studies. The groundwork for the standard for pathology reporting was finally published after a Delphi Consensus process by Klimstra et al. [25] in 2010, and the diagnostic sequences for the pathological diagnosis of NETs are now well defined. It requires more than $50 \%$ of cells to stain positive for one of the neuroendocrine markers, synaptophysin or chromogranin. Tumors demonstrating lower percentages of cells with positive staining can be either designated as mixed adenoneuroendocrine carcinoma (MANEC) or a carcinoma with neuroendocrine differentiation. These should not be considered as, nor treated as a NET, and ENETS emphasized this fact by finally completely removing the goblet cell carcinoid (a misnomer) from the appendix NET guidelines [26]. ENETS produced its pathology grading system for foregut and midgut NETs in 2007 [27, 28]. Two landmark papers were published explaining how this grading system should work. Since then, several groups have published on the clinical usefulness of such a system, and until now the cut-off criteria for the different tumor grades did not need to be changed [29-31]. Recently the cut-off for grading has been changed in the new WHO 2017 guideline: a very slight change in the grade 1-2 cutoff has been implemented (grade 1: Ki67 $\leq 3 \%$ ) [32]. This small change will probably not influence clinical practice, but the newly advised classifying of grade 3 tumors can possibly change future guidelines. The WHO 2017 guideline advises to classify NETs with a Ki67 $>20 \%$ as either grade 3 NET (well-differentiated) or as grade 3 NEC (poorly differentiated) on the basis of morphological characteristics as necrosis and differentiation. Grade 3 NEC should hardly always be treated with systemic chemotherapy, whilst in well-differentiated grade 3 NET, there might still be room for PRRT or targeted therapy. To aid in the grading of NETs immunohistochemical markers can be useful. Loss of Rb or ab- normal p53 expression is often seen in grade 3 NEC, while loss of ATRX and DAXX expression is associated with well-differentiated NETs [33].

After the correct diagnosis of NET, staging should always be performed. ENETS has been leading the effort for a standardized approach. On behalf of ENETS, Rindi et al. $[27,28]$ published a TNM classification for NETs and this is also used in guidelines produced by ENETS and many other international studies and groups. A similar staging system was developed by the International Union for Cancer Control/American Joint Cancer Committee/ World Health Organization (UICC/AJCC/WHO), although there are several differences identified between these two major systems. In a head to head comparison in a large cohort of pancreatic NETs, the ENETS system performed generally better [34]. In future guidelines, prognostic stratification through molecular markers may take a more prominent role [35].

\section{Surgery}

Early ENETS guidelines already defined preoperative standards and recognized the importance of a correct preoperative biochemical analysis. Especially patients with a small intestinal NET should be screened for serotonin secretion by determining 5-hydroxyindoleacetic acid levels in the urine or plasma. Patients with elevated levels of this serotonin breakdown product might require SSA therapy to prevent carcinoid crises during surgery or other invasive procedures [36,37]. ENETS recently updated its recommendations in this field [38]. The only curative option for NETs has always been a surgical resection, and this has not changed until now and probably will remain for a long period of time $[4,39]$. But while surgery can always be considered, current guidelines also define selected patients who might not need immediate treatment and just have to be observed according to a welldefined watchful waiting protocol. Observation seems reasonable in pancreatic NETs smaller than $2 \mathrm{~cm}$; however, follow-up was only limited to 3 or 4 years in these studies [40, 41]. Importantly, these recommendations are based on studies in patients with inherited tumor syndromes, like von Hippel Lindau disease, or MEN-1. As always, larger cohorts and preferably studies randomizing between observation or intervention would shed further light on this issue. The generally slow growth rate of small pancreatic NETs will, however, require such a long follow-up and a large study cohort rendering further studies almost infeasible. Shared decision-making will 
probably remain the standard for small nonfunctioning pancreatic NET in the coming years. However, ENETS has developed a plan to further study these issues in its ASPEN trial [42]. The second pancreatic or duodenal NET type that should not be primarily resected is the gastrinoma in MEN-1 patients. At presentation, these are often metastasized to lymph nodes requiring extensive resections (like pancreaticoduodenectomy) [43, 44]. Curation rates are lower in MEN-1 patients, but prognosis is still better than in patients with sporadic gastrinomas [45]. Only in MEN-1 patients with multiple liver metastases of gastrinomas is the survival significantly reduced $[45,46]$. Therefore, in most MEN-1 patients with a gastrinoma smaller than $2 \mathrm{~cm}$, only medical therapy with proton pump inhibitors (PPIs) is recommended and SSAs in patients with symptoms refractory to PPIs [47, 48].

The extent of resection for appendiceal NETs also remains a matter of debate. A large majority of appendiceal NETs are diagnosed incidentally during appendectomy, and most are often smaller than $1 \mathrm{~cm}$. Appendectomy alone suffices for these patients as long-term survival is near $100 \%$ [26]. For appendiceal NETs larger than $2 \mathrm{~cm}$, the risk of (lymph node) metastasis has been reported to be close to $25 \%$ with one study even finding lymph node metastases in $86 \%$ of these NET patients [49-51]. A right hemicolectomy is still recommended for these NETs, but in high-risk patients this procedure can result in morbidity in up to $30 \%$ of patients $[26,52]$. The survival benefit of this procedure has never been demonstrated. Hemicolectomy is still advised for appendiceal NETs $>2 \mathrm{~cm}$, but new and better evidence is urgently needed to select patients for this procedure.

For nonresectable or metastatic NETs, there has been a large increase in different therapeutic options. On the surgical side, there is further debate on whether resection of the primary tumor is indicated. Resection is currently recommended if curation can still be reached by resecting the primary including all metastases or in symptomatic patients (e.g., with abdominal pain or diarrhea) [53]. Some studies also suggest a benefit for resection of the primary in asymptomatic, incurable patients increasing overall survival from 50 to 88 months in small bowel NET patients not undergoing resection to over 100 months in patients undergoing resection [54]. These studies, however, are retrospective, and a large bias is very likely due to the selection of patients for surgery based on performance status and extent of mesenteric fibrosis.

\section{Systemic Therapy}

Multiple medical therapies have become available for the treatment of metastatic NETs. All have shown their effect in randomized controlled trials, but head-to-head comparisons are not available. It is, therefore, difficult to select which drug is the most suitable for a selected patient. ENETS has developed an algorithm for treatment of metastatic NET aiding in the selection of the most suitable treatment for individual patients [55].

\section{Somatostatin Analogs}

The earliest ENETS guidelines could only recommend commencing SSAs in patients with functioning (hormone or peptide secreting) NETs since clinical evidence for their growth-inhibiting potential in nonfunctioning NETs was not available at that time. However, experimental studies as well as clinical experience in individual cases had already hinted at these effects $[4,56]$. The recommendations were based on reduction of biomarkers and symptoms in patients with carcinoid syndrome, and only data on the initial responses were available (stable disease in $24-57 \%$ of patients). Nowadays, there is substantial clinical evidence for the antiproliferative effect of SSAs. In the preENETS era, Scandinavian studies already showed growth inhibition in NETs with treatment of high doses of SSAs $[57,58]$. First published was the PROMID trial, demonstrating that $30 \mathrm{mg}$ of octreotide LAR every 4 weeks increased median progression-free survival (PFS) from 6.0 months (placebo) to 14.3 months in patients with a metastatic small intestinal NET [59]. This trial included also patients with not so severe carcinoid syndrome (36\% of patients). The CLARINET trial followed several years later: including pancreatic and small intestinal NETs, median PFS increased from 18.0 months for placebo to median PFS not reached for lanreotide $120 \mathrm{mg}$ every 4 weeks [60]. These results combined with the high tolerability finally led to ENETS advising first-line SSA treatment for patients with a pancreatic or small intestinal NET with a Ki67 tumor index of $10 \%$ or less [55]. Besides SSAs, ENETS separately published instructions for safe use of systemic therapy. [61]. Future interests lie in optimal dosing of SSAs, new forms of SSAs (single versus multiple SSA receptor), new formulations and whether to continue SSAs during second-line therapy, like PRRT using radiolabeled SSAs and targeted therapy.

\section{Peptide Receptor Radionuclide Therapy}

In the early ENETS guidelines, evidence for PRRT with radiolabeled SSAs was limited. The first large obser- 
vational study on PRRT using ${ }^{177} \mathrm{Lu}$-octreotate, including 310 patients with gastroenteropancreatic NET was only published in 2008 by Kwekkeboom et al. [62]. A median PFS of 40 months was reported, which at that time was far superior to any other available therapy (chemotherapy or interferon- $\alpha$ ). This was the basis for the recently published NETTER-1 trial: patients with metastasized small intestinal NET were randomized to ${ }^{177} \mathrm{Lu}$-DOTA-octreotate or octreotide LAR $60 \mathrm{mg}$ per 4 weeks [63]. Median PFS was not reached in the PRRT arm at publication of the trial in 2017 after more than 2.5 years of follow-up, while median PFS in the octreotide LAR arm was 8.4 months (hazard ratio: $0.21 ; 95 \%$ CI: $0.13-0.33 ; p<0.001$ ). Through this trial, ${ }^{177} \mathrm{Lu}$-DOTA-octreotate will probably be the first widely approved agent for PRRT. The ENETS Standard of Care for PRRT clearly describes evidence, treatment protocols, and patient selection for treatment with PRRT [64].

\section{Targeted Therapy}

The major advances in the field of targeted therapy for NETs can hardly be left unnoticed. Targeted therapy was first included in the ENETS guidelines of 2012 [65]. Currently, both sunitinib and everolimus are registered for the treatment of progressive metastatic pancreatic NET, and everolimus is also registered for progressive metastatic small intestinal NET [55].

Everolimus was studied in at least 3 large randomized controlled trials. First published in 2011, the RADIANT-3 trial studied patients with a progressive pancreatic NET, and in this trial everolimus increased PFS to 11.0 months compared to 4.6 months when treated with placebo (HR 0.35 , 95\% CI: $0.27-0.45 ; p<0.001$ ) [66]. Shortly thereafter, the RADIANT-2 and RADIANT- 4 trials were also published, studying PFS respectively in patients with carcinoid syndrome and nonfunctional NETs [67, 68]. Again, everolimus was shown to increase PFS with an HR for progression of, respectively, 0.77 (95\% CI: 0.59-1.00, $p=0.026$ one-sided) and 0.48 (95\% CI: 0.35-0.67, $p<$ 0.001 one-sided), but toxicity is higher than treatment with SSAs [66-68].

Sunitinib has been studied in pancreatic NETs. In the SUNNET trial with 171 patients with a pancreatic NET, sunitinibincreased PFS from 5.5 (placebo) to 11.4 months, resulting in a hazard ratio of 0.42 for progression (95\% CI: 0.26-0.66, <0.001 two-sided) [69].

There is no specific preference for sunitinib or everolimus in progressive pancreatic NET as head-to-head comparisons are not available and, therefore, selection of therapy still is depending on the physician's preferences and/or multidisciplinary team's opinions [55]. For example, for the patient with hypertension everolimus could be more suitable and vice versa for the patient with diabetes. The characteristics and treatment of side effects have been described in the standard of care for systemic therapy [61]. An important role for ENETS will continue to be the judging of the available evidence for drugs to advise the clinician through its guidelines on selecting the most appropriate drug for the patient.

\section{Interferon-Alpha}

From the first guideline onwards, interferon-alpha has been recommended as second-line treatment after progression during treatment on SSAs $[4,55]$. Interferon is a cytokine that has antiproliferative and antisecretory effect in NETs [70]. Our knowledge on the response to interferon is largely based on the work of Öberg et al. [7173 ] in the 1990s. Partial response occurs in around 10$15 \%$ of NETs, and this is comparable to treatment with SSAs. However, the burden of evidence for SSAs is higher, and the unfavorable side effects of interferon make SSAs the first-line treatment for metastatic NETs [74]. These side effects consist of flu-like symptoms and fatigue. While interferon is still recommended as second-line drug, newer therapies as PRRT and immunotherapy have less side effects, higher efficacy, and are supported by more evidence. A pegylated formulation, administered weekly, can decrease side effects [75]. The role of interferon in future guidelines will probably be reduced to selected patients with refractory carcinoid syndrome.

\section{Chemotherapy}

For the treatment of poorly differentiated grade 3 NECs, chemotherapy is the first option. NECs are treated similar to small cell lung carcinomas, with platinumbased chemotherapy, and this is stated in all ENETS guidelines $[4,76]$. The combination of cisplatin with etoposide results in relatively high response rates of $17-67 \%$, but median survival is still only 7-19 months [76-78]. Platinum-based chemotherapy has only little effect in NETs with Ki67 of $20-55 \%$, and the use should be limited to poorly differentiated grade 3 NECs. New in current guidelines is the growing burden of evidence for secondline treatments with oxaliplatin- or irinotecan-based regimes [76, 77].

Since the first study of Moertel et al. [79] in 1980, the combination of streptozotocin and 5-fluorouracil (STZ/5FU) has been used for treatment of metastatic pancreatic NET. At that time, grading was not performed, and therefore STZ/5-FU could potentially be used in all metastatic 
pancreatic NET. The 2016 ENETS guidelines limit the use of STZ/5-FU to NETs with a Ki67 of 5-20\%, with bulky disease or rapid progression [55]. There is no evidence for chemotherapy in small intestinal NETs [80, 81]. Chemotherapy with temozolomide and capecitabine is currently not recommended by ENETS due to lack of evidence, but it shows promising results in phase II trials [55]. Combining chemotherapy with targeted inhibitors of angiogenesis (bevacizumab) looks promising, but has not proven superior to current regimes [82].

\section{Interventional Radiology}

Lastly, there have been major developments in the fields of interventional radiology for the treatment of NETs. Radiofrequency ablation is a commonly used technique for liver metastases smaller than $5 \mathrm{~cm}$ [83]. Larger tumors, especially in patients with liver-only disease, can be treated with embolization. Multiple options for embolization exist, namely bland embolization, chemoembolization, or radioembolization. At this time, no preference can be made for a certain treatment due to lack of comparative trials, but especially bland embolization and radioembolization with ${ }^{90}$ Ytrium show a very promising response rate of up to $80 \%$ in selected studies, but on average around 50\% (complete and partial response) [84-86]. Currently, no standard of care by ENETS exists for embolization, but it is included in the current guidelines for selected patients with high liver burden.

\section{Future Perspectives}

When we compare the current with the past guidelines, it is clear that the field of NET research has come a long way in the past decades. It is impossible to measure the exact impact of these guidelines on patient care, but they do reflect the vast developments in the field. The first guidelines by ENET could only recommend a few diagnostic and treatment options with limited evidence to support the guidelines [2]. There has been a large increase in diagnostic accuracy with the development of the ${ }^{68} \mathrm{Ga}$-SSA PET/CT, and the pathology reporting has been standardized to correctly diagnose patients and to select correct treatment. Multiple randomized controlled trials have been published demonstrating the antiproliferative effect of SSAs, targeted therapy and PRRT with radiolabeled SSAs. But the burden of evidence has also significantly increased: the first guideline was based on limited data and expert opinion mainly, but the most recent guidelines are based on prospective trials and are much more capable of quantifying benefits of diagnostics and treatments. The most robust association, proving the effects of the guidelines is that with increasing treatment options in the guidelines, an increasing survival for NET patients has been recorded. ENETS of course does not develop new treatments, but the main role of ENETS should be to critically appraise the available evidence and therewith facilitate the transfer of knowledge to the clinicians and advise these clinicians on the correct treatment for their patients with the expertise of specialists behind the guidelines. With increasing burden of evidence, an important next step for ENETS is to develop the next guidelines with levels of evidence and strength of recommendations [87]. Also, ENETS should highlight important clinical questions which are currently unanswered, resulting in unclear or unsupported recommendations. They are already doing so, and this has resulted in promising future research and trials. One of the main clinical enigmas remains the choice of second-line therapy when patients are progressive while using SSA. PRRT with radiolabeled SSAs, targeted therapy and several chemotherapy regimens have been proven effective in progressive patients. The results of the NETTER-1 trial are superior to any therapy presently available and will most probably become the second-line therapy of choice. However, the sequence of therapy is arbitrary and based on the inclusion criteria for trials. The first true trial on sequencing therapy has recently been initiated in collaboration with ENETS: the SEQTOR trial compares the sequence of consecutively STZ/5-FU and everolimus [88].

But also in the surgical field, many questions remain. For which appendiceal NET is hemicolectomy indicated, and should we resect the primary tumor in metastatic small intestinal NET? But also, can surveillance be justified in small pancreatic NETs? ENETS have initiated prospective trials studying resection of the primary and surveillance of small pancreatic NET.

Outside the guidelines, ENETS have developed their Centers of Excellence programs. The greatest benefit for patients is that expert centers are clearly identifiable, but also that patient care is monitored by the yearly submission of treatment data for quality control.

In conclusion, the guideline is only a small part in patient care. Reaching a high standard of patient care starts with organizing scientific meetings to exchange basic science on which the eventual treatments of the future are based and ends with monitoring the quality of care at the bedside through the ENETS Centers of Excellence pro- 
gram. In between lie the guidelines which advise the clinician on the treatment of choice. The effect of the ENETS guidelines on patient care cannot simply be quantified, as end points would be biased and flawed, but sometimes evidence is not necessary to notice the benefit.
For the ENETS guidelines, this benefit lies in its advice to the unexperienced clinician, the critical appraisal of the literature, and the identification of gaps in current evidence.

\section{References}

$1 \mathrm{http}: / /$ www.enets.org/what_is_enets.html.

2 Ricke J, Klose KJ, Mignon M, Oberg K, Wiedenmann B: Standardisation of imaging in neuroendocrine tumours: results of a European delphi process. Eur J Radiol 2001;37:817.

3 Vezzosi D, Bennet A, Courbon F, Caron P: Short- and long-term somatostatin analogue treatment in patients with hypoglycaemia related to endogenous hyperinsulinism. Clin Endocrinol (Oxf) 2008;68:904-911.

-4 Plockinger U, Rindi G, Arnold R, Eriksson B, et al: Guidelines for the diagnosis and treatment of neuroendocrine gastrointestinal tumours. A consensus statement on behalf of the European Neuroendocrine Tumour Society (ENETS). Neuroendocrinology 2004;80: 394-424.

-5 Sundin A, Arnold R, Baudin E, Cwikla JB, et al: ENETS Consensus Guidelines for the Standards of Care in Neuroendocrine Tumors: Radiological, Nuclear Medicine and Hybrid Imaging. Neuroendocrinology 2017; 105: 212-244.

-6 Elias D, Lefevre JH, Duvillard P, Goere D, Dromain C, Dumont F, Baudin E: Hepatic metastases from neuroendocrine tumors with a "thin slice" pathological examination: they are many more than you think. Ann Surg 2010;251:307-310.

7 Krenning EP, Bakker WH, Breeman WA, Koper JW, Kooij PP, Ausema L, Lameris JS, Reubi JC, Lamberts SW: Localisation of endocrine-related tumours with radioiodinated analogue of somatostatin. Lancet 1989;1:242244.

8 de Herder WW, Hofland LJ, van der Lely AJ, Lamberts SW: Somatostatin receptors in gastroentero-pancreatic neuroendocrine tumours. Endocr Relat Cancer 2003;10:451458.

9 Lebtahi R, Cadiot G, Sarda L, Daou D, Faraggi M, Petegnief Y, Mignon M, le Guludec D: Clinical impact of somatostatin receptor scintigraphy in the management of patients with neuroendocrine gastroenteropancreatic tumors. J Nucl Med 1997;38:853-858.

10 Balon HR, Brown TL, Goldsmith SJ, Silberstein $\mathrm{EB}$, et al: The SNM practice guideline for somatostatin receptor scintigraphy 2.0. J Nucl Med Technol 2011;39:317-324.
11 Balon HR, Goldsmith SJ, Siegel BA, Silberstein EB, Krenning EP, Lang O, Donohoe KJ; Society of Nuclear Medicine: Procedure guideline for somatostatin receptor scintigraphy with (111)In-pentetreotide. J Nucl Med 2001;42:1134-1138.

12 Buchmann I, Henze M, Engelbrecht S, Eisenhut M, Runz A, Schafer M, Schilling T, Haufe S, Herrmann T, Haberkorn U: Comparison of 68Ga-DOTATOC PET and 111In-DTPAOC (Octreoscan) SPECT in patients with neuroendocrine tumours. Eur J Nucl Med Mol Imaging 2007;34:1617-1626.

13 Gabriel M, Decristoforo C, Kendler D, Dobrozemsky G, Heute D, Uprimny C, Kovacs P, Von Guggenberg E, Bale R, Virgolini IJ: 68Ga-DOTA-Tyr3-octreotide PET in neuroendocrine tumors: comparison with somatostatin receptor scintigraphy and CT. J Nucl Med 2007;48:508-518.

14 Geijer H, Breimer LH: Somatostatin receptor PET/CT in neuroendocrine tumours: update on systematic review and meta-analysis. Eur J Nucl Med Mol Imaging 2013;40:1770-1780.

15 Johnbeck CB, Knigge U, Kjaer A: PET tracers for somatostatin receptor imaging of neuroendocrine tumors: current status and review of the literature. Future Oncol 2014;10:22592277.

16 Yang J, Kan Y, Ge BH, Yuan L, Li C, Zhao W: Diagnostic role of Gallium-68 DOTATOC and Gallium-68 DOTATATE PET in patients with neuroendocrine tumors: a meta-analysis. Acta Radiol 2014;55:389-398.

17 Ambrosini V, Nanni C, Zompatori M, Campana D, Tomassetti P, Castellucci P, Allegri V, Rubello D, Montini G, Franchi R, Fanti S: (68) Ga-DOTA-NOC PET/CT in comparison with CT for the detection of bone metastasis in patients with neuroendocrine tumours. Eur J Nucl Med Mol Imaging 2010;37:722727.

18 Putzer D, Gabriel M, Henninger B, Kendler D, Uprimny C, Dobrozemsky G, Decristoforo C, Bale RJ, Jaschke W, Virgolini IJ: Bone metastases in patients with neuroendocrine tumor: 68Ga-DOTA-Tyr3-octreotide PET in comparison to CT and bone scintigraphy. J Nucl Med 2009;50:1214-1221.

19 Poeppel TD, Binse I, Petersenn S, Lahner H, Schott M, Antoch G, Brandau W, Bockisch A, Boy C: $68 \mathrm{Ga}$-DOTATOC versus $68 \mathrm{Ga}-\mathrm{DOT}$ ATATE PET/CT in functional imaging of neuroendocrine tumors. J Nucl Med 2011;52: 1864-1870.
20 Velikyan I, Sundin A, Sorensen J, Lubberink M, Sandstrom M, Garske-Roman U, Lundqvist H, Granberg D, Eriksson B: Quantitative and qualitative intrapatient comparison of $68 \mathrm{Ga}$-DOTATOC and 68Ga-DOTATATE: net uptake rate for accurate quantification. J Nucl Med 2014;55:204-210.

21 Binderup T, Knigge U, Loft A, Mortensen J, Pfeifer A, Federspiel B, Hansen CP, Hojgaard L, Kjaer A: Functional imaging of neuroendocrine tumors: a head-to-head comparison of somatostatin receptor scintigraphy, 123IMIBG scintigraphy, and 18F-FDG PET. J Nucl Med 2010;51:704-712.

22 Binderup T, Knigge U, Loft A, Federspiel B, Kjaer A: 18F-fluorodeoxyglucose positron emission tomography predicts survival of patients with neuroendocrine tumors. Clin Cancer Res 2010;16:978-985.

23 Kashyap R, Hofman MS, Michael M, Kong G, Akhurst T, Eu P, Zannino D, Hicks RJ: Favourable outcomes of (177)Lu-octreotate peptide receptor chemoradionuclide therapy in patients with FDG-avid neuroendocrine tumours. Eur J Nucl Med Mol Imaging 2015; 42:176-185.

24 Perren A, Couvelard A, Scoazec JY, Costa F, et al: ENETS Consensus Guidelines for the Standards of Care in Neuroendocrine Tumors: Pathology: Diagnosis and Prognostic Stratification. Neuroendocrinology 2017;105: 196-200.

25 Klimstra DS, Modlin IR, Coppola D, Lloyd RV, Suster S: The pathologic classification of neuroendocrine tumors: a review of nomenclature, grading, and staging systems. Pancreas 2010;39:707-712.

26 Pape UF, Niederle B, Costa F, Gross D, et al: ENETS Consensus Guidelines for Neuroendocrine Neoplasms of the Appendix (Excluding Goblet Cell Carcinomas). Neuroendocrinology 2016;103:144-152.

27 Rindi G, Kloppel G, Couvelard A, Komminoth P, Korner M, Lopes JM, McNicol AM, Nilsson O, Perren A, Scarpa A, Scoazec JY, Wiedenmann B: TNM staging of midgut and hindgut (neuro) endocrine tumors: a consensus proposal including a grading system. Virchows Arch 2007;451:757-762.

28 Rindi G, Kloppel G, Alhman H, Caplin M, et al: TNM staging of foregut (neuro)endocrine tumors: a consensus proposal including a grading system. Virchows Arch 2006;449: 395-401. 
-29 Pape UF, Jann H, Muller-Nordhorn J, Bockelbrink A, Berndt U, Willich SN, Koch M, Rocken C, Rindi G, Wiedenmann B: Prognostic relevance of a novel TNM classification system for upper gastroenteropancreatic neuroendocrine tumors. Cancer 2008;113:256265.

- 30 Strosberg J, Nasir A, Coppola D, Wick M, Kvols L: Correlation between grade and prognosis in metastatic gastroenteropancreatic neuroendocrine tumors. Hum Pathol 2009; 40:1262-1268.

- 31 Dhall D, Mertens R, Bresee C, Parakh R, Wang HL, Li M, Dhall G, Colquhoun SD, Ines D, Chung F, Yu R, Nissen NN, Wolin E: Ki-67 proliferative index predicts progression-free survival of patients with well-differentiated ileal neuroendocrine tumors. Hum Pathol 2012;43:489-495.

32 Lloyd RV, Osamura RY, Klöppel G, Rosai J, Bosman FT, Jaffe ES, Lakhani SR, Ohgaki H (eds), World Health Organization, International Agency for Research on Cancer: WHO Classification of Tumours of Endocrine Organs, ed 4. Geneva, World Health Organization, 2017.

- 33 Tang LH, Basturk O, Sue JJ, Klimstra DS: A practical approach to the classification of WHO grade 3 (G3) well-differentiated neuroendocrine tumor (WD-NET) and poorly differentiated neuroendocrine carcinoma (PDNEC) of the pancreas. Am J Surg Pathol 2016; 40:1192-1202.

34 Rindi G, Falconi M, Klersy C, Albarello L, et al: TNM staging of neoplasms of the endocrine pancreas: results from a large international cohort study. J Natl Cancer Inst 2012; 104:764-777.

-35 Oberg K: The genetics of neuroendocrine tumors. Semin Oncol 2013;40:37-44.

-36 Partelli S, Bartsch DK, Capdevila J, Chen J, et al: ENETS Consensus Guidelines for Standard of Care in Neuroendocrine Tumours: Surgery for Small Intestinal and Pancreatic Neuroendocrine Tumours. Neuroendocrinology 2017;105:255-265.

- 37 Oberg K, Couvelard A, Delle Fave G, Gross D, et al: ENETS Consensus Guidelines for Standard of Care in Neuroendocrine Tumours: Biochemical Markers. Neuroendocrinology 2017;105:201-211.

- 38 Kaltsas G, Caplin M, Davies P, Ferone D, et al: ENETS Consensus Guidelines for the Standards of Care in Neuroendocrine Tumors: Pre- and Perioperative Therapy in Patients with Neuroendocrine Tumors. Neuroendocrinology 2017;105:245-254.

-39 Wiedenmann B, Jensen RT, Mignon M, Modlin CI, Skogseid B, Doherty G, Oberg K: Preoperative diagnosis and surgical management of neuroendocrine gastroenteropancreatic tumors: general recommendations by a consensus workshop. World J Surg 1998;22:309318.
40 Sadot E, Reidy-Lagunes DL, Tang LH, Do RK, Gonen M, D'Angelica MI, DeMatteo RP, Kingham TP, Groot Koerkamp B, Untch BR, Brennan MF, Jarnagin WR, Allen PJ: Observation versus resection for small asymptomatic pancreatic neuroendocrine tumors: a matched case-control study. Ann Surg Oncol 2016;23:1361-1370.

41 Gaujoux S, Partelli S, Maire F, D’Onofrio M, Larroque B, Tamburrino D, Sauvanet A, Falconi M, Ruszniewski P: Observational study of natural history of small sporadic nonfunctioning pancreatic neuroendocrine tumors. J Clin Endocrinol Metab 2013;98:4784-4789.

42 Asymptomatic Small Pancreatic Endocrine Neoplasms. NCT03084770, 2017.

43 Norton JA, Fraker DL, Alexander HR, Jensen RT: Value of surgery in patients with negative imaging and sporadic Zollinger-Ellison syndrome. Ann Surg 2012;256:509-517.

44 Giovinazzo F, Butturini G, Monsellato D, Malleo G, Marchegiani G, Bassi C: Lymph nodes metastasis and recurrences justify an aggressive treatment of gastrinoma. Updates Surg 2013;65:19-24.

45 Weber HC, Venzon DJ, Lin JT, Fishbein VA, Orbuch M, Strader DB, Gibril F, Metz DC, Fraker DL, Norton JA, et al: Determinants of metastatic rate and survival in patients with Zollinger-Ellison syndrome: a prospective long-term study. Gastroenterology 1995;108: 1637-1649.

-46 Yu F, Venzon DJ, Serrano J, Goebel SU, Doppman JL, Gibril F, Jensen RT: Prospective study of the clinical course, prognostic factors, causes of death, and survival in patients with long-standing Zollinger-Ellison syndrome. J Clin Oncol 1999;17:615-630.

47 Falconi M, Eriksson B, Kaltsas G, Bartsch DK, et al: ENETS Consensus Guidelines Update for the Management of Patients with Functional Pancreatic Neuroendocrine Tumors and Non-Functional Pancreatic Neuroendocrine Tumors. Neuroendocrinology 2016; 103:153-171.

48 Ruszniewski P, Podevin P, Cadiot G, Marmuse JP, Mignon M, Vissuzaine C, Bonfils S, Lehy T: Clinical, anatomical, and evolutive features of patients with the Zollinger-Ellison syndrome combined with type I multiple endocrine neoplasia. Pancreas 1993;8:295-304.

49 Mullen JT, Savarese DM: Carcinoid tumors of the appendix: a population-based study. J Surg Oncol 2011;104:41-44.

50 Moertel CG, Weiland LH, Nagorney DM, Dockerty MB: Carcinoid tumor of the appendix: treatment and prognosis. N Engl J Med 1987;317:1699-1701.

51 Fornaro R, Frascio M, Sticchi C, De Salvo L, Stabilini C, Mandolfino F, Ricci B, Gianetta E: Appendectomy or right hemicolectomy in the treatment of appendiceal carcinoid tumors? Tumori 2007;93:587-590.
52 Bokey EL, Chapuis PH, Fung C, Hughes WJ, Koorey SG, Brewer D, Newland RC: Postoperative morbidity and mortality following resection of the colon and rectum for cancer. Dis Colon Rectum 1995;38:480-486; discussion 486-487.

53 Niederle B, Pape UF, Costa F, Gross D, et al: ENETS Consensus Guidelines Update for Neuroendocrine Neoplasms of the Jejunum and Ileum. Neuroendocrinology 2016;103: 125-138.

54 Capurso G, Rinzivillo M, Bettini R, Boninsegna L, Delle Fave G, Falconi M: Systematic review of resection of primary midgut carcinoid tumour in patients with unresectable liver metastases. Br J Surg 2012;99:1480-1486.

55 Pavel M, O’Toole D, Costa F, Capdevila J, et al: ENETS Consensus Guidelines Update for the Management of Distant Metastatic Disease of Intestinal, Pancreatic, Bronchial Neuroendocrine Neoplasms (NEN) and NEN of Unknown Primary Site. Neuroendocrinology 2016;103:172-185.

56 Imam H, Eriksson B, Lukinius A, Janson ET, Lindgren PG, Wilander E, Oberg K: Induction of apoptosis in neuroendocrine tumors of the digestive system during treatment with somatostatin analogs. Acta Oncol (Stockholm) 1997;36:607-614.

57 Eriksson B, Janson ET, Bax ND, Mignon M, Morant R, Opolon P, Rougier P, Oberg KE: The use of new somatostatin analogues, lanreotide and octastatin, in neuroendocrine gastro-intestinal tumours. Digestion 1996; 57(suppl 1):77-80.

58 Eriksson B, Renstrup J, Imam H, Oberg K: High-dose treatment with lanreotide of patients with advanced neuroendocrine gastrointestinal tumors: clinical and biological effects. Ann Oncol 1997;8:1041-1044.

59 Rinke A, Muller HH, Schade-Brittinger C, Klose KJ, et al: Placebo-controlled, doubleblind, prospective, randomized study on the effect of octreotide LAR in the control of tumor growth in patients with metastatic neuroendocrine midgut tumors: a report from the PROMID Study Group. J Clin Oncol 2009;27:4656-4663.

60 Caplin ME, Pavel M, Ruszniewski P: Lanreotide in metastatic enteropancreatic neuroendocrine tumors. N Engl J Med 2014;371: 1556-1557.

61 Pavel M, Valle JW, Eriksson B, Rinke A, et al: ENETS Consensus Guidelines for the Standards of Care in Neuroendocrine Neoplasms: Systemic Therapy - Biotherapy and Novel Targeted Agents. Neuroendocrinology 2017; 105:266-280

62 Kwekkeboom DJ, de Herder WW, Kam BL, van Eijck CH, van Essen M, Kooij PP, Feelders RA, van Aken MO, Krenning EP: Treatment with the radiolabeled somatostatin analog [177 Lu-DOTA 0, Tyr3]octreotate: toxicity, efficacy, and survival. J Clin Oncol 2008;26: 2124-2130. 
-63 Strosberg J, El-Haddad G, Wolin E, Hendifar A, et al: Phase 3 Trial of 177Lu-Dotatate for Midgut Neuroendocrine Tumors. N Engl J Med 2017;376:125-135.

-64 Hicks RJ, Kwekkeboom DJ, Krenning E, Bodei L, et al: ENETS Consensus Guidelines for the Standards of Care in Neuroendocrine Neoplasia: Peptide Receptor Radionuclide Therapy with Radiolabeled Somatostatin Analogues. Neuroendocrinology 2017;105:295309.

65 Pavel M, Baudin E, Couvelard A, Krenning E, et al: ENETS Consensus Guidelines for the management of patients with liver and other distant metastases from neuroendocrine neoplasms of foregut, midgut, hindgut, and unknown primary. Neuroendocrinology 2012; 95:157-176.

66 Yao JC, Shah MH, Ito T, Bohas CL, et al: Everolimus for advanced pancreatic neuroendocrine tumors. N Engl J Med 2011;364:514523.

67 Pavel ME, Hainsworth JD, Baudin E, Peeters $\mathrm{M}$, et al: Everolimus plus octreotide long-acting repeatable for the treatment of advanced neuroendocrine tumours associated with carcinoid syndrome (RADIANT-2): a randomised, placebo-controlled, phase 3 study. Lancet 2011;378:2005-2012.

68 Yao JC, Fazio N, Singh S, Buzzoni R, et al: Everolimus for the treatment of advanced, non-functional neuroendocrine tumours of the lung or gastrointestinal tract (RADIANT-4): a randomised, placebo-controlled, phase 3 study. Lancet 2016;387:968-977.

69 Raymond E, Dahan L, Raoul JL, Bang YJ, Borbath I, Lombard-Bohas C, Valle J, Metrakos P, Smith D, Vinik A, Chen JS, Horsch D, Hammel P, Wiedenmann B, Van Cutsem E, Patyna S, Lu DR, Blanckmeister C, Chao R, Ruszniewski P: Sunitinib malate for the treatment of pancreatic neuroendocrine tumors. N Engl J Med 2011;364:501-513.

70 Platanias LC: Mechanisms of type-I- and type-II-interferon-mediated signalling. Nat Rev Immunol 2005;5:375-386.

71 Oberg K, Funa K, Alm G: Effects of leukocyte interferon on clinical symptoms and hormone levels in patients with mid-gut carcinoid tumors and carcinoid syndrome. N Engl J Med 1983;309:129-133.

72 Oberg K, Eriksson B: The role of interferons in the management of carcinoid tumours. $\mathrm{Br}$ J Haematol 1991;79(suppl 1):74-77.
3 Oberg K: Interferon-alpha versus somatostatin or the combination of both in gastroenteropancreatic tumours. Digestion 1996; 57(suppl 1):81-83.

74 Eriksson B, Kloppel G, Krenning E, Ahlman $\mathrm{H}$, et al: Consensus guidelines for the management of patients with digestive neuroendocrine tumors-well-differentiated jejunalileal tumor/carcinoma. Neuroendocrinology 2008;87:8-19.

-75 Pavel ME, Baum U, Hahn EG, Schuppan D, Lohmann T: Efficacy and tolerability of pegylated IFN-alpha in patients with neuroendocrine gastroenteropancreatic carcinomas. J Interferon Cytokine Res 2006;26:8-13.

76 Garcia-Carbonero R, Sorbye H, Baudin E, Raymond E, et al: ENETS Consensus Guidelines for High-Grade Gastroenteropancreatic Neuroendocrine Tumors and Neuroendocrine Carcinomas. Neuroendocrinology 2016;103:186-194.

-77 Sorbye H, Welin S, Langer SW, Vestermark LW, Holt N, Osterlund P, Dueland S, Hofsli E, Guren MG, Ohrling K, Birkemeyer E, Thiis-Evensen E, Biagini M, Gronbaek H, Soveri LM, Olsen IH, Federspiel B, Assmus J, Janson ET, Knigge U: Predictive and prognostic factors for treatment and survival in 305 patients with advanced gastrointestinal neuroendocrine carcinoma (WHO G3): the NORDIC NEC study. Ann Oncol 2012;24:152-160.

78 Moertel CG, Kvols LK, O’Connell MJ, Rubin J: Treatment of neuroendocrine carcinomas with combined etoposide and cisplatin. Evidence of major therapeutic activity in the anaplastic variants of these neoplasms. Cancer 1991;68:227-232.

79 Moertel CG, Hanley JA, Johnson LA: Streptozocin alone compared with streptozocin plus fluorouracil in the treatment of advanced islet-cell carcinoma. N Engl J Med 1980;303: 1189-1194.

-80 Sun W, Lipsitz S, Catalano P, Mailliard JA, Haller DG; Eastern Cooperative Oncology Group: Phase II/III study of doxorubicin with fluorouracil compared with streptozocin with fluorouracil or dacarbazine in the treatment of advanced carcinoid tumors: Eastern Cooperative Oncology Group Study E1281. J Clin Oncol 2005;23:4897-4904.
81 Dahan L, Bonnetain F, Rougier P, Raoul JL, et al: Phase III trial of chemotherapy using 5 -fluorouracil and streptozotocin compared with interferon alpha for advanced carcinoid tumors: FNCLCC-FFCD 9710. Endocr Relat Cancer 2009;16:1351-1361.

82 Ducreux M, Adenis A, Pignon JP, Francois E, Chauffert B, Ichante JL, Boucher E, Ychou M, Pierga JY, Montoto-Grillot C, Conroy T: Efficacy and safety of bevacizumab-based combination regimens in patients with previously untreated metastatic colorectal cancer: final results from a randomised phase II study of bevacizumab plus 5-fluorouracil, leucovorin plus irinotecan versus bevacizumab plus capecitabine plus irinotecan (FNCLCC ACCORD 13/0503 study). Eur J Cancer 2013;49: 1236-1245.

83 de Baere T, Elias D, Dromain C, Din MG, Kuoch V, Ducreux M, Boige V, Lassau N, Marteau V, Lasser P, Roche A: Radiofrequency ablation of 100 hepatic metastases with a mean follow-up of more than 1 year. AJR Am J Roentgenol 2000;175:1619-1625.

84 de Baere T, Deschamps F, Tselikas L, Ducreux M, Planchard D, Pearson E, Berdelou A, Leboulleux S, Elias D, Baudin E: GEP-NETS update: interventional radiology: role in the treatment of liver metastases from GEPNETs. Eur J Endocrinol 2015;172:R151R166.

85 Devcic Z, Rosenberg J, Braat AJ, Techasith T, Banerjee A, Sze DY, Lam MG: The efficacy of hepatic $90 \mathrm{Y}$ resin radioembolization for metastatic neuroendocrine tumors: a meta-analysis. J Nucl Med 2014;55:1404-1410.

86 Maire F, Lombard-Bohas C, O’Toole D, Vullierme MP, Rebours V, Couvelard A, Pelletier AL, Zappa M, Pilleul F, Hentic O, Hammel P, Ruszniewski P: Hepatic arterial embolization versus chemoembolization in the treatment of liver metastases from well-differentiated midgut endocrine tumors: a prospective randomized study. Neuroendocrinology 2012; 96:294-300.

87 Qaseem A, Snow V, Owens DK, Shekelle P, et al: The development of clinical practice guidelines and guidance statements of the American College of Physicians: summary of methods. Ann Intern Med 2010;153:194-199.

88 Efficacy and safety of everolimus and (STZ$5 \mathrm{FU}$ ) given one upfront the other upon progression in advanced pNET (SEQTOR). https://clinicaltrialsgov/ct2/show/study/ NCT02246127?show_locs=Y\#locn. 